\title{
Factors Related to the Likelihood of Hiring a Health Advocate
}

\author{
Jordan A. Carlson, Jenny E. Imberi, Terry A. Cronan,Miguel T. Villodas, \\ Kimberly C. Brown \& Gregory A. Talavera
}

San Diego State University, Department of Psychology

\begin{abstract}
This study was designed to explore factors related to the likelihood of hiring a health advocate. Independent variables were selected from the health service use model to capture predisposing, enabling, and illness-level factors. Participants were 889 adults ( $\mathrm{M}$ age $=50.9$ years, $\mathrm{SD}=17.9$ years, $52 \%$ female) recruited from a large cultural park in San Diego, California during the spring and summer of 2008. Participants read a description of a health advocate and completed a brief set of questions on age, gender, confidence in health care, effort maintaining health, self-rated health, and the likelihood of hiring a health advocate. Hierarchical regression analysis revealed that participants age 40-64, non-Caucasians , participants who exerted more effort maintaining their health, and participants 65 and older who were less satisfied with their social support reported greater likelihood of hiring a health advocate. Findings were similar to those of studies that applied the health service use model to predict use of other health services, such as medical visits. These findings suggest factors that health care organizations offering health advocacy services could consider when targeting potential clients.
\end{abstract}

(c) 2011 Californian Journal of Health Promotion. All rights reserved.

Keywords: health care, advocacy, navigator, health behavior, health services

\section{Introduction}

The health care system is becoming increasingly complex and difficult to navigate, and patients are increasingly dissatisfied with their physicians and other health care services (Frosch \& Kaplan, 1999; Gagnon, Hebert, Dube \& Dubois, 2006; Kizer, 2001). Partly in response to these problems, services are being offered to increase treatment quality and patient satisfaction with the health care system (Hurst, n.d). These services have been referred to as health advocacy (Hurst, n.d; Schwartz, 2002), patient advocacy (Willard, 1996), client navigators (Weinrich, Boyd, Weinrich, Greene, Reynolds \& Metlin, 1998), and patient navigators (Dohan \& Schrag, 2005). These services can include accompanying patients to doctor's visits, staying overnight in the hospital with a patient, providing emotional support and encouragement, scheduling appointments, assisting with insurance issues, and researching treatment options for the patient. For the purpose of the present study, we refer to these types of services as "health advocacy" services.

Health advocacy originated in the patient rights movement in the 1970's (Hurst, n.d) and can be community based (Hiatt et al., 2001), hospital based (Willard, 1996), government based (Freeman, Muth, \& Kerner, 1995; Frelix, Rosenblatt, Solomon \& Vikram, 1999; National Cancer Institute [NCI], 2009), or offered by private organizations (Pinnacle Care, n.d).

Health advocacy services benefit patients by increasing access to health care services (Shannon, Wilber \& Allen, 2006), increasing patients' knowledge about their condition or treatment (Saliminen, Isoaho, Vahlberg, Ojanlatva, \& Kivela, 2005), and increasing cancer screening among patients (Weinrich et al., 1998). Freeman, Muth, and Kerner (1995) developed a "patient navigator" program to help underserved patients overcome barriers to obtaining cancer screenings and found that 
patients who used the patient navigator waited less time for follow-up physician visits after obtaining cancer screenings. Scholle and colleagues (2000) reported that women were more likely to receive information and recommendations on breast cancer screenings when a health advocate was present; Freeman (2006) found that breast cancer patients reported significantly better diagnoses and increased 5year survival rates when using a patient navigator.

Although researchers have investigated the effectiveness and benefits of health advocacy programs, they have not investigated health advocacy services offered by private organizations. Such health advocates are important because they can be hired for pay, meaning that anyone with enough money can use them. Knowing the factors that are related to a person's likelihood of hiring a health advocate may help health care facilitators, organizations, and researchers to design and implement health advocacy services to target patients who will be most interested in and receptive to these types of services.

Andersen and Newman (1973) developed a theoretical model for predicting use of health services that incorporates three individual-level components: the predisposition of the person to use services (i.e., demographic and belief factors), his/her ability to secure services (i.e., financial status), and his/her illness level (i.e., health status). Factors within this model have been found to predict hospital visits, physician visits, and aide services (Aday \& Awe, 1997). However, no research has examined individuallevel factors that might influence a person's likelihood of hiring a health advocate or similar service. The present study explores whether predisposing, enabling, and illness-level factors within the health service use framework are associated with self-reported likelihood of hiring a health advocate in a convenience sample of the general public.

In the present study, it was predicted that findings would be similar to those of other studies investigating the role of factors within the Andersen and Newman model in understanding health service use. These studies have indicated that, among other factors, older people (Barer, Evans, Hertzman, \& Lomas, 1987; Yang, Norton, \& Stearns, 2003), women (Lonnquist, Weiss, \& Larsen, 1992), people who value their health (Aday \& Awe, 1997), and people in poor health (Miller \& McFall, 1991) are more likely to use health services than their counterparts. Health advocacy could be a mechanism to increase use of health services (i.e., regular physician visits) by people who are less likely to use health services because of barriers such as ethnic or economic disparities and negative beliefs regarding health care service, assuming that these individuals can afford health advocacy services (Freeman et al., 1995, Salminen et al., 2005; Scholle, Agatisa, Krohn, Johnson \& McLaughlin, 2000; Shannon et al., 2006; Weinrich et al., 1998). Therefore, we predicted that factors within the Andersen and Newman model that are associated with greater need for health services, based on the aforementioned barriers, would also be related to a person's likelihood of using a health advocate. These factors include minority status, low income, lack of satisfaction with social support, and lack of confidence in health care providers. However, it is important to note that, because a health advocate is someone who can be hired for pay, those with greater need because of their economic disadvantage may be more interested in obtaining the assistance of a health care advocate, but may not be more likely to hire a health advocate because they lack the necessary financial resources.

\section{Method}

\section{Study Design}

This study used a cross-sectional design to explore factors that may be associated with the likelihood of hiring a health advocate. The choice was made to measure likelihood of hiring a health advocate (i.e. a hypothetical behavior) as opposed to assessing use of a health advocate for two reasons. First, the services of a health advocate are relatively new, and it would require greater resources than those available for this study to find and recruit participants who had used a health advocate. Second, because the hypotheses were drawn from data based on 
sampling of the general population, the hypotheses should be tested in a similar population.

\section{Participants and Procedures}

Participants were 889 adults aged 18 or older, recruited from Balboa Park, a large cultural park in San Diego, California. Balboa Park is situated on 1200 acres and is home to 15 major museums, several performance art venues, public gardens and the San Diego Zoo. This park receives more than 500,000 visitors a year from all over the world. This location was selected as a data collection site because the large number of visitors made for convenient sampling. The mean age of participants was $50.94(\mathrm{SD}=17.9)$ years, and most of them were married $(52 \%)$. The median income was less than $\$ 80,000$ (see Table 1 for more descriptive information about the sample).

Research staff alternated between surveying men and women so approximately equal numbers of each gender were recruited. Focusing on one gender at a time, staff used a random number generator (numbers ranged from 1-5) to select the first, second, third, fourth, or fifth man or woman who walked by. Potential participants were asked whether they would like to participate in a short survey; if the person declined, the staff immediately approached the next person who walked by. Interested participants were asked whether they understood and read English and resided in the United States. If they met these eligibility criteria, they read and signed an informed consent form and continued with the study. Participants were asked to read a description explaining a health advocate as "someone a person could hire to help with a health problem and its treatment. Examples of what a health care advocate might do are: go with the patient to doctor's visits, ask medical questions on behalf of the person, provide emotional support and encouragement, help schedule appointments and keep notes, file or discuss medical payments with an insurance carrier or Medicare/MediCal, and/or even stay overnight with a hospitalized person to insure that all his/her needs are met." Participants completed an anonymous questionnaire and were paid $\$ 5$ for their time. Data were collected in the spring and summer of 2008. This study was approved by the San Diego State University Institutional Review Board.

\section{Measures}

The measures were chosen to represent constructs within Andersen and Newman's model. According to this model, the likelihood of hiring a health advocate is related to three levels of factors: the predisposition of the individual (including demographic and belief factors), his/her level of resources (these enabling factors relate to a person's ability to hire a health advocate or navigate health care without a health advocate, including his/her income, health insurance status, and social support), and his/her illness level (which is related to his/her need for hiring a health advocate). The measures were brief so that several constructs could be measured with as little burden on the participant as possible. Thus, most constructs were measured using a single item.

\section{Predisposing Factors - Demographics}

Participants' gender, ethnicity, marital status and age (in years) were recorded.

\section{Predisposing Factors - Beliefs}

Two dimensions were used to assess the participants' health beliefs. The first dimension was participants' self-reported effort devoted to maintaining their health. The question asked "how much effort do you put into maintaining your health" and response options ranged from 1 (no effort) to 5 (a great deal of effort). Studies have shown that health motivation and the amount of effort people devote to maintaining their health are related to various health behaviors, intentions, and outcomes (Gochman, 1972). The second dimension was participants' ratings of their confidence in the health care they receive. Four questions asked "how confident are you in your: (1) health care coverage, (2) hospitals, (3) physicians, and (4) general medical staff," and response options ranged from 1 (no confidence) to 10 (a great deal of confidence). Items were adapted from the Health Confidence Survey (Employee Benefit Research 
Institute, 2006).

\section{Enabling Factors}

Three dimensions of enabling factors were assessed. The first was participants' annual household income on a six-point scale, ranging from 1 (less than $\$ 50,000$ ) to 6 (above $\$ 180,000)$ in increments of $\$ 30,000$. The second was whether or not participants had medical insurance. The third dimension was satisfaction with social support. Social support was defined as "people you can readily count on for help with a health care problem or illness," and satisfaction with social support was measured using a single item asking "how satisfied are you with your social support?" (Franks, Cronan \& Oliver, 2004). Response options ranged from 1 (not at all) to 5 (a great deal).

\section{Illness Factors}

Illness was assessed with one item requiring participants to rate their health, using a 5-point scale ranging from 1 (poor) to 5 (excellent). This item was borrowed from the SF-36 (Ware \& Sherbourne, 1992) and is a good predictor of many health outcomes (Kaplan \& Camancho, 1983).

\section{Dependent Variable}

The dependent variable was participants' likelihood of hiring a health advocate. It was measured using one item asking "How likely would you be to hire a health advocate in the future," and responses were rated on a 10-point Likert-type scale ranging from 1 (not at all likely) to 10 (extremely likely).

\section{Analysis}

All analyses presented in the present study were conducted using SPSS version 16. Ethnicity was recoded to represent the comparison between Caucasians and all other ethnic minority groups,

Table 1

\begin{tabular}{|c|c|}
\hline \multicolumn{2}{|c|}{ Descriptive Statistics for Variables in Model. $\mathbf{N}=\mathbf{8 8 9}$} \\
\hline & Frequency $(\%)$ \\
\hline \multicolumn{2}{|l|}{ Predisposing Factors - Demographics } \\
\hline Gender (Female) & $462(52 \%)$ \\
\hline Ethnicity (Minority) & $187(21 \%)$ \\
\hline Younger than 40 & $258(29 \%)$ \\
\hline Between 40 and 64 & $418(47 \%)$ \\
\hline Older than 64 & $213(24 \%)$ \\
\hline \multicolumn{2}{|l|}{ Predisposing Factors - Beliefs } \\
\hline Confidence in Health Care (High) & $498(56 \%)$ \\
\hline Effort Maintaining Health (High) & $605(68 \%)$ \\
\hline \multicolumn{2}{|l|}{ Enabling Factors } \\
\hline Income (Below $\$ 80,000)$ & $507(57 \%)$ \\
\hline \multirow{2}{*}{ Health Insurance (Yes) } & $791(89 \%)$ \\
\hline & Mean (SD) \\
\hline Satisfaction with Social Support & $3.95(1.01)$ \\
\hline \multicolumn{2}{|l|}{ Past Illness } \\
\hline Self-Rated Health & $3.65(.92)$ \\
\hline \multicolumn{2}{|l|}{ Dependent Variable } \\
\hline Likelihood of Hiring a Health Advocate & $4.28(2.78)$ \\
\hline
\end{tabular}

who were treated as a single group because of the low number of ethnic minority respondents. The distribution of the age variable suggested that three primary groups of respondents could be identified: participants older than 18 and younger than 40; participants between 40 and 64; and participants 65 and older. A median split was performed on the income variable, which 
resulted in dividing the sample into participants who earned $\$ 80,000$ per year or more and those who earned less than $\$ 80,000$ per year.

For confidence in the health care system, the average score of the four items was calculated to create a single sum score for each participant (Cronbach's $\alpha=.89$ ). Because the distribution of these scores was severely skewed, and other transformations did not sufficiently correct for skewness, responses were dichotomized, using a median split: participants whose score was 7.49 or less and participants whose score was 7.5 or higher. Similarly, participants' scores on effort maintaining health were also dichotomized, using a median split because of severe skewness, into participants who responded 3 or less and participants who responded 4 or higher.

A hierarchical multiple regression was conducted with likelihood of hiring a health advocate as the criterion variable and predisposing factors - demographics (age, gender, and ethnicity) entered on step 1, predisposing factors - beliefs (confidence in the health care system and effort maintaining health) entered on step 2, enabling factors (income, health insurance, and satisfaction with social support) entered on step 3, illness factors (selfrated health) entered on step 4 , and interaction terms (interaction between age and satisfaction with social support) entered on step 5 (see Table 2 ). The categorical variable, age, was dummycoded to examine comparisons between the age groups. Individuals 65 and older were coded as the reference category in the first analysis and individuals younger than 40 were then re-coded as the reference category in order to examine all possible comparisons. The proportion of variance explained by each subsequent step $\left(\Delta R^{2}\right)$ is presented along with the $p$-value for the total model.

\section{Results}

On step 1 of the hierarchical multiple regression, the predisposing factors - demographics accounted for a significant amount of overall variance in likelihood of hiring a health advocate $\left(\mathrm{R}^{2}=.023, P=.003\right)$. People between 40 and 64 were more likely to indicate that they would hire a health advocate than were people older than 64 $(\beta=.121, P=.014)$. Ethnic minority participants reported a greater likelihood of hiring a health advocate than did Caucasians $(\beta$ $=.084, P=.034)$. Women tended to be more likely to indicate that they would hire a health advocate than men $(\beta=.072, P=.061)$.

Step 2, which added predisposing factors beliefs, accounted for a significant amount of variance $\left(\Delta \mathrm{R}^{2}=.036, P<.001\right)$. Participants who exerted more effort maintaining their health indicated a higher likelihood of hiring a health advocate $(\beta=.195, P<.001)$.

Step 3, which added enabling factors, did not account for a significant amount of variance $\left(\Delta \mathrm{R}^{2}=.003, P=.491\right)$. Similarly, step 4 which added illness factors did not account for a significant amount of variance $\left(\Delta \mathrm{R}^{2}=.003, P=\right.$ $.153)$.

Finally, step 5 which added the interaction between social support and age, accounted for a significant amount of variance $\left(\Delta \mathrm{R}^{2}=.012, P=\right.$ $.013)$.

There was a significant interaction between satisfaction with social support and the comparison between people older than 64 and people younger than $40(\beta=.152, P=.016)$. Similarly, there was a significant interaction between satisfaction with social support and the comparison between participants between the ages of 40 and 64 and participants younger than $40(\beta=-.154, P=.015)$. The interaction between satisfaction with social support and the comparison between participants older than 64 and participants between the ages of 40 and 64 was not statistically significant $(\beta=.037, P=$ $.646)$. 
Table 2

Effects of Andersen-Newman Model Variables on Likelihood of Hiring a Health Advocate

\begin{tabular}{|c|c|c|c|}
\hline & $\Delta \mathrm{R}^{2}$ & Standardized $\beta$ & $\begin{array}{l}\text { Unstandardized B }(95 \% \\
\text { Confidence Interval })^{\mathrm{a}}\end{array}$ \\
\hline Predisposing Factors - Demographics (Step 1) & .023 & & \\
\hline Gender & & .072 & $.101^{\mathrm{b}}(-.005, .206)$ \\
\hline Ethnicity & & .084 & $.149 *(.011, .286)$ \\
\hline $18-39$ vs. 65 and older & & .091 & $.139(-.012, .290)$ \\
\hline $40-64$ vs. 65 and older & & .121 & $.170 *(.034, .306)$ \\
\hline 40-64 vs. $18-39$ & & .022 & $.031(-.093, .155)$ \\
\hline$\frac{\text { Predisposing Factors - Beliefs }}{\text { (Step 2) }}$ & .036 & & \\
\hline Confidence in Health Care & & -.034 & $-.048(-.156, .060)$ \\
\hline Effort Maintaining Health & & .195 & $.288 * * *(.176, .400)$ \\
\hline Enabling Factors & .003 & & \\
\hline (Step 3) & & & \\
\hline Income & & -.003 & $-.004(-.113, .105)$ \\
\hline Insurance & & .042 & $.090(-.082, .262)$ \\
\hline Satisfaction with Social Support & & -.048 & $-.068(-.179, .043)$ \\
\hline Illness Factors & .003 & & \\
\hline$\overline{(\text { Step 4) }}$ & & & \\
\hline Self-Rated Health & & -.057 & $-.130(-.308, .048)$ \\
\hline$\frac{\text { Interactions }}{\text { (Sten 5) }}$ & .012 & & \\
\hline $\begin{array}{l}18-39 \text { vs. } 65 \text { and older by Satisfaction with } \\
\text { Social Support }\end{array}$ & & .152 & $.391 *(.095, .686)$ \\
\hline $\begin{array}{l}40-64 \text { vs. } 65 \text { and older by Satisfaction with } \\
\text { Social Support }\end{array}$ & & .037 & $.075(-.196, .347)$ \\
\hline $\begin{array}{l}40-64 \text { vs. } 18-39 \text { by Satisfaction with } \\
\text { Social Support }\end{array}$ & & -.154 & $-.315^{*}(-.558,-.073)$ \\
\hline
\end{tabular}

To explore this interaction further, the relationship between satisfaction with social support and likelihood of hiring a health advocate was statistically evaluated, using regression analyses in each age group while controlling for all other predictor variables (i.e., predisposing factors - demographics and beliefs, enabling factors, and illness factors; see Figure 1). Satisfaction with social support approached significance and was positively related to likelihood of hiring a health advocate for participants under $40, \beta=.135, P=.050$; among participants between 40 and 64, satisfaction with social support was not significantly related to likelihood of hiring a health advocate, $\beta=-.093$, $P=.126$; among participants over 64, satisfaction with social support was significantly and negatively related to likelihood of hiring a health advocate, $\beta=-.171, P=.038$. Thus, people under 40 tended to be more likely to report that they would hire a health advocate if they were more satisfied with their social support, while people over 64 were more likely to report that they would hire a health advocate if they were less satisfied with their social support. Satisfaction with social support was not related to likelihood of hiring a health advocate for people between 40 and 64 . 
Figure 1

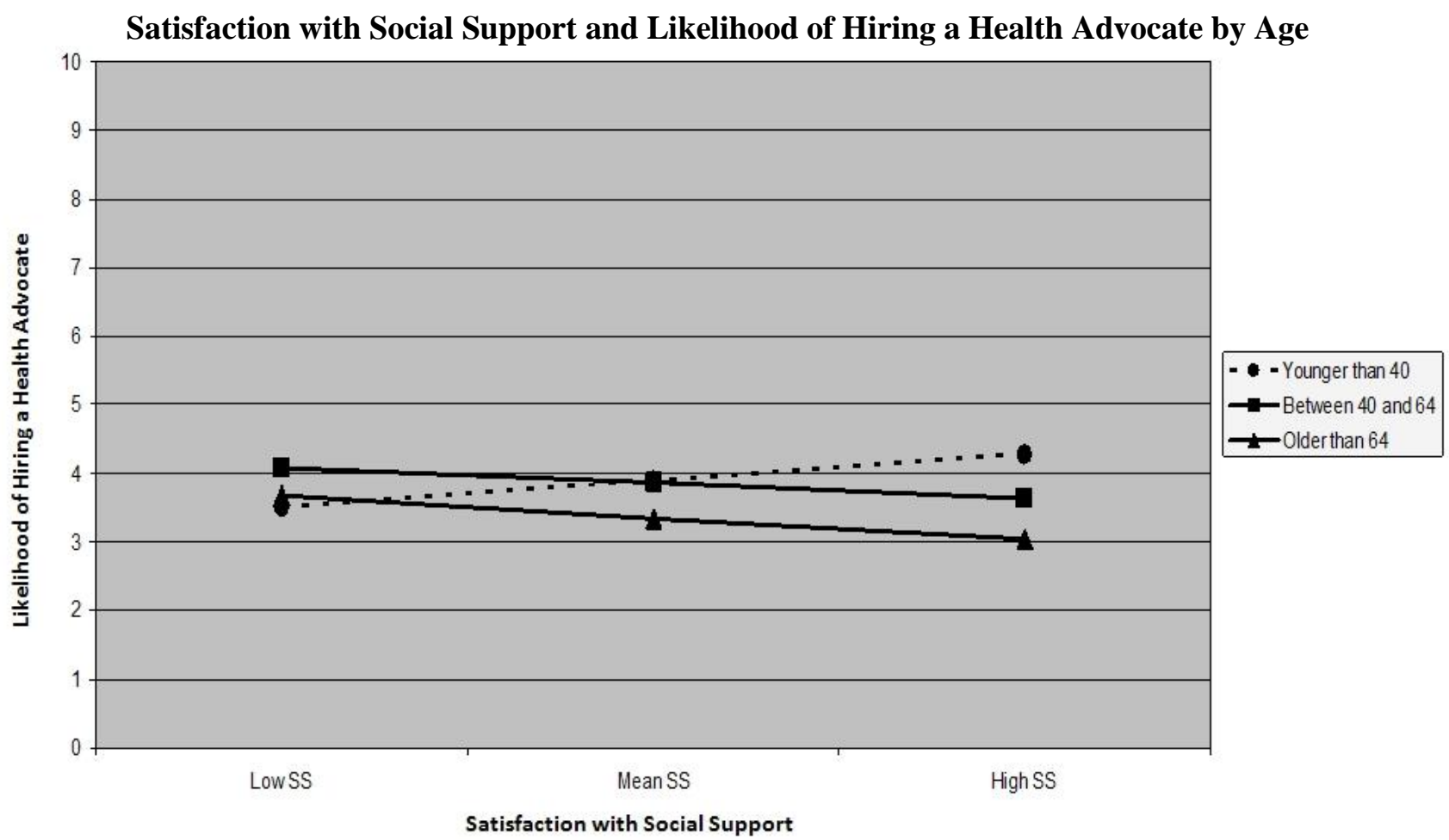

\section{Discussion}

The results of the present study demonstrated that factors identified within Andersen and Newman's model of health service use were related to self-reported likelihood of hiring a health advocate in a convenience sample of the general public. Specifically, predisposing factors - demographics and predisposing factors predicted likelihood of hiring a health advocate. The strongest predictor of reported likelihood of hiring a health advocate was the amount of effort participants reported exerting to maintain their health. These findings are consistent with other studies indicating that demographic factors and health beliefs are related to health service use and other health behaviors (Aday \& Awe, 1997; Andersen \& Newman, 1973; Gilson, 2003; Roghmann, Hengst, \& Zastowny, 1979; Ross, Steward \& Sinacore, 1993). However, contrary to previous studies, enabling and illness factors were not associated with reported likelihood of hiring a health advocate, with the exception of social support in individuals aged
65 and older (Aday \& Awe, 1997; Andersen \& Newman, 1973).

People between 40 and 64 years of age also reported greater likelihood of hiring an advocate than older people. This is contrary to expectations based on previous findings (Aday $\&$ Awe, 1997). The difference in reported likelihood of hiring a health advocate for men versus women approached significance, indicating that women may or may not be more likely to hire a health advocate, contrary to findings using the Andersen and Newman model to investigate use of other health services (Aday \& Awe, 1997).

Factors within the Andersen and Newman model that are associated with greater need for health services, based on economic and attitudinal barriers, were also related to a person's reported likelihood of hiring a health advocate. Specifically, non-Caucasians and older participants who were less satisfied with their social support reported greater likelihood of 
hiring a health advocate. Minorities reported a greater likelihood of hiring a health advocate than Caucasians, possibly because they viewed a health advocate as someone who could help them gain access to better health services. It was also predicted that participants with lower satisfaction with social support would reported greater likelihood of hiring a health advocate because they would view a health advocate as someone who could offer support when dealing with an illness (Wortman \& Conway, 1985). This hypothesis was supported in the 65 and older group, but not in younger participants. Studies have shown that satisfaction with social support is important in predicting health outcomes (Brown, Wallston \& Nisassio; 1989; Franks et al., 2004, Sarason, Sarason \& Pierce, 1990).

Factors that were not associated with reported likelihood of hiring a health advocate were participants' confidence in health care, income, health insurance, and self-rated health. These findings were contrary to predictions and to previous studies (Aday \& Awe 1997; Andersen \& Newman, 1973). It is especially interesting that participants' confidence in health care and their health status were not related to reported likelihood of hiring a health advocate.

It was predicted that participants with lower household income would reported greater likelihood of hiring a health advocate to help them gain better access to health services. However, it was acknowledged that, while someone with economic disparities might benefit from hiring a health advocate, they might not have the financial resources to pay for one. The present study did not find a relationship between income and reported likelihood of hiring a health advocate. It is possible that income is related to likelihood of hiring a health advocate, but that participants in this study did not fully consider their finances in responding to the question because their responses were to a hypothetical situation. Future studies could investigate this research question further by including more low-income participants and asking about willingness to use, as opposed to hire, a health advocate.

\section{Limitations}

The brief description of a health advocate used in the present study may not have captured all aspects of the services that a health advocate could provide. Thus participants may have not fully understood what a health advocate was, or they may have used prior knowledge and interpretations regarding health advocacy when responding to survey questions. Also, this study measured the hypothetical behavior of reported likelihood of hiring a health advocate, not the actual use of a health advocate. Intentions do not always predict behaviors (Sutton, 1998). A person's intentions may change in different situations or circumstances, and barriers may prevent a person from engaging in a behavior, even though she or he intended to perform that behavior (Sutton, 1998).

Most measures in this study used single items to measure complex constructs in an attempt to include multiple factors within the Andersen and Newman framework, while limiting participant burden. Although these measures may not have fully captured the constructs they were intended to measure, most were borrowed from published studies and have adequate face validity. Also, because this study used a convenience sample, these findings do not represent the general population. In particular, the median household income in this sample was around $\$ 80,000$, which is above the median household income in the county in which the study was conducted, and is well above the U.S. average. This study may not generalize to non-English speakers. Future studies should investigate clinical populations and minority groups, as these populations may be the most likely to use and benefit from health advocacy services.

\section{Conclusion}

Although some studies have shown that using a health advocate or similar service is beneficial (Freeman et al., 1995; Freeman, 2006; Salminen et al., 2005; Scholle et al., 2000; Weinrich et al., 1998), further research is needed to evaluate the effects of using a health advocate. Specifically, researchers should investigate the effects of a health advocate on patient satisfaction, wellbeing, health care costs, and other health 
outcomes. Researchers should also target and examine health advocacy within specific groups. The present study suggests which groups could be targeted, such as those with greater need for health services (i.e. minorities, older people with lower satisfaction with their social support) and those who exert more effort in maintaining their health.

In summary, there is an increasing interest in health advocacy, and it is important to investigate the circumstances that are most likely to lead a person to hire a health advocate. This exploratory study identified factors that should be further investigated in large, randomized trials. Identifying factors related to hiring a health advocate could inform health care facilitators, organizations, and researchers designing health advocacy services about patients who may be the most receptive to, and have the greatest potential to benefit from, health advocacy services. Ultimately, more research and policy decisions about health advocacy may lead to significant increases in a multitude of health outcomes, including quality of care, patient satisfaction, and a reduction in overall health care costs (Hurst, n.d).

\section{References}

Aday, L. A., \& Awe, W. C. (1997). Health services utilization models. In D. S. Gochman (Ed.), Handbook of Health Behavior Research I: Personal and Social Determinants (pp. 153-172). New York and London: Plenum Press.

American Hospital Association [AHA]. (2002). In the name of the patient: Consumer advocacy in healthcare. Society for Healthcare Consumer Advocacy, Chicago, Il.

Andersen, R., \& Newman, J. F. (1973). Societal and individual determinants of medical care utilization in the United States. The Milbank Memorial Fund Quarterly, Health and Society, 51(1), 95-124.

Barer, M. L., Evans, R. G., Hertzman, C., \& Lomas, J. (1987). Aging and health care utilization: New evidence on old fallacies. Social Science \& Medicine, 24(10), 851-862.

Brown, G. K., Wallston, K. A., \& Nicassio, P. M. (1989). Social support and depression in rheumatoid arthritis: A one-year prospective study. Journal of Applied Social Psychology, 19(14), 1164-1181.

Dohan, D., \& Schrag, D. (2005). Using navigators to improve care of underserved patients. Cancer, 104(4), 848-855.

Employee Benefit Research Institute. (2006, November). 2006 Health confidence survey: Dissatisfaction with health care system doubles since 1998 (Issue Brief No. 27). Washington, DC: Helman, R., Greenwald, M., \& Fronstin, P.

Fiscella, K., Franks, P., Gold, M. R., \& Clancy, C. M. (2000). Inequality in quality: Addressing socioeconomic, racial, and ethnic disparities in health care. Journal of the American Medical Association, 283(19), 2579-2584.

Franks, H. M., Cronan, T. A., \& Oliver, K. (2004). Social support in women with fibromyalgia: Is quality more important than quantity? Journal of Community Psychology 32(4), 425-438.

Freeman, H. P. (2006). Patient navigation: A community based strategy to reduce cancer disparities. Journal of Urban Health, 83(2), 139-141.

Freeman, H. P., Muth, B. J., \& Kerner, J. F. (1995). Expanding access to cancer screening and clinical follow-up among the medically underserved. Cancer Practice, 3(1), 19-30.

Frelix, G. D., Rosenblatt, R., Solomon, M., \& Vikram, B. (1999). Breast cancer screening in underserved women in the Bronx. Journal of the National Medical Association, 91(4), 195-200.

Frosch, D. L., \& Kaplan, R. M. (1999). Shared decision making in clinical medicine: Past research and future directions. American Journal of Preventive Medicine, 17(4), 285-294.

Gagnon, M., Hebert, R., Dube, M., \& Dubois, M. F. (2006). Development and validation of the health care satisfaction questionnaire (HCSQ) in elders. Journal of Nursing Measurement, 14(3), 190204.

Gilson, L. (2003). Trust and the development of health care as a social institution. Social Science \& Medicine, 56(7), 1453-1468. 
Gochman, D. S. (1972). The organizing role of motivation in health beliefs and intentions. Journal of Health and Social Behavior, 13(3), 285-293.

Hall, M. A., Dugan, E., Zheng, B., \& Mishra, A. K. (2001). Trust in physicians and medical institutions: What is it, can it be measured, and does it matter? Milbank Quarterly, 79(4), 613-639.

Hiatt, R. A., Pasick, R. J., Stewart S., Bloom, J., Davis, P., Gardiner, P., et al. (2001). Community-based cancer screening for underserved women: Design and baseline findings from the breast cancer and cervical cancer intervention study. Preventive Medicine, 33(3), 190-203.

Hurst, M. (n.d.). Health advocacy: Defining the field. Retrieved September 15, 2008, from Sarah Lawrence College, Health Advocacy Program Web site: http://www.slc.edu/graduate/programs/health-advocacy/Defining_the_Field.html

Kaplan, G. A., \& Camacho, T. (1983). Perceived health and mortality: A nine-year follow-up of the Human Population Laboratory cohort. American Journal of Epidemiology, 117(3), 292-304.

Kizer, K. W. (2001). Establishing health care performance standards in an era of consumerism. JAMA, 286(10), 1213-1217.

Lonnquist, L. E., Weiss, G. L., \& Larsen, D. L. (1992). Health value and gender in predicting health protective behavior. Women's Health, 19(2), 69-85.

Miller, B., \& McFall, S. (1991). The effect of caregiver's burden on change in frail older persons' use of formal helpers. Journal Health and Social Behavior, 32(2), 165-179.

Mustard, C. A., Kaufert, P., Kozyrskyj, A., \& Mayer, T. (1998). Sex differences in the use of health care services. New England Journal of Medicine, 338(23), 1678-1683.

National Cancer Institute [NCI]. (2005). NCI's patient navigator research program: Fact sheet. Retrieved May 5, 2009, from http://www.cancer.gov/cancertopics/factsheet/PatientNavigator

Pinnacle Care. (n.d.). Personalized healthcare: About Pinnacle Care Private Health Advisory. Retrieved May 13, 2009, from http://www.pinnaclecare.com/about_pinnaclecare/overview/

Roghmann, K. J., Hengst, A., \& Zastowny, T. R. (1979). Satisfaction with medical care: Its measurement and relation to utilization. Medical Care, 17(5), 461-479.

Ross, C. K., Steward, C. A., \& Sinacore, J. M. (1993). The importance of patient preferences in the measurement of health care satisfaction. Medical Care, 31(12), 1138-1149.

Salminen, M., Isoaho, R., Vahlberg, T., Ojanlatva, A., \& Kivela, S. (2005). Effects of a health advocacy, counselling, and activation programme on depressive symptoms in older coronary heart disease patients. International Journal of Geriatric Psychiatry, 20(6), 552-558.

Sarason, I., Sarason, B., \& Pierce, G. (1990). Social support: The search for theory. Journal of Social \& Clinical Psychology, 9(1), 133-147.

Scholle, S. H., Agatisa, P. K., Krohn, M. A., Johnson, J., \& McLaughlin, M. K. (2000). Locating a health advocate in a private obstetrics/gynecology office increases patients' receipt of preventive recommendations. Journal of Women's Health \& Gender-Based Medicine, 9(2), 161-165.

Schwartz, L. (2002). Is there an advocate in the house? The role of health care professionals in health advocacy. Journal of Medical Ethics, 28, 37-40.

Shannon, G. R., Wilber, K. H., \& Allen, D. (2006). Reductions in costly healthcare service utilization: findings from the care advocate program. Journal of the American Geriatrics Society, 54(7), 1102-1107.

Sutton, S. (1998). Predicting and explaining intentions and behavior: How well are we doing? Journal of Applied Social Psychology, 28(15), 1317-1338.

Ware, J.E. Jr., \& Sherbourne, C. D. (1992). The MOS 36-item short-form health survey (SF-36): I. Conceptual framework and item selection. Medical Care, 30(6), 473-483.

Weinrich, S. P., Boyd, M. D., Weinrich, M., Greene, F., Reynolds, W. A. Jr., \& Metlin, C. (1998). Increasing prostate cancer screening in African American men with peer-educator and clientnavigator interventions. Journal of Cancer Education, 13(4), 213-219.

Willard, C. (1996). The nurse's role as patient advocate: obligation or imposition? Journal of Advanced Nursing, 24(1), 60-66. 
Wortman, C. B., \& Conway, T. L. (1985). The role of social support in adaptation and recovery from physical illness. In S. Cohen, \& L. S. Syme (Eds.), Social support and health (pp. 281-302). New York, NY: Academic Press.

Yang, Z., Norton, E. C., \& Stearns, S. C. (2003). Longevity and health care expenditures: The real reasons older people spend more. The Journals of Gerontology Series B: Psychological Sciences and Social Sciences, 58(1), S2-S10.

Author Information

Jordan A. Carlson, M.A.*

San Diego State University

Department of Psychology

5500 Campanile Dr.

San Diego, CA 92182

Phone: 619-594-6915

Fax: 619-594-1332

Email: jcarlson@projects.sdsu.edu

Jenny E. Imberi, M.A.

Department of Psychology

San Diego State University, San Diego, CA

Terry A. Cronan, Ph.D.*

Department of Psychology

San Diego State University, San Diego, CA

Miguel T. Villodas, M.S.

Department of Psychology

San Diego State University, San Diego, CA

Kimberly C. Brown, M.A.

Department of Psychology

San Diego State University, San Diego, CA

Gregory A. Talavera, M.D., M.P.H.

Graduate School of Public Health

San Diego State University, San Diego, CA

* corresponding author 